\title{
Four-weekly Low-dose Gemcitabine and Paclitaxel in Patients With Platinum-resistant Urothelial Cancer and Performance Status 2/3
}

\author{
KYOHEI ARAKI, YASUYOSHI MIYATA, YUICHIRO NAKAMURA, YUTA MUKAE, ASATO OTSUBO, \\ TSUTOMU YUNO, KENSUKE MITSUNARI, TOMOHIRO MATSUO, KOJIRO OHBA and HIDEKI SAKAI \\ Department of Urology, Nagasaki University Graduate School of Biomedical Sciences, Nagasaki, Japan
}

\begin{abstract}
Background/Aim: Immune check-point inhibitors are often unsuitable for patients with urothelial cancer with a poor performance status (PS 2 or 3). The aim of this study was to assess the safety and usefulness of combined therapy with low-dose gemcitabine and paclitaxel every 4 weeks. Patients and Methods: Thirty patients were treated with gemcitabine (700 mg/m $\mathrm{m}^{2}$ on day 1) and paclitaxel $\left(70 \mathrm{mg} / \mathrm{m}^{2}\right.$ on day 1) every 4 weeks. The predictive value of human antigen-R $(H u R)$ and class III $\beta$-tubulin (TUBB3) were also analyzed. Results: There was no severe adverse event nor significant decrease in quality of life. The survival period of patients treated with this regimen was significantly longer than that of those treated with best supportive care. The expression pattern of HUR negativity and TUBB3 positivity predicted significantly worse overall survival. Conclusion: Our regimen was suitable as second-line therapy for patients with advanced platinum-resistant UC with a poor PS. However, a HuR-negative and TUBB3-positive expression pattern appears to confer poorer outcome.
\end{abstract}

Urothelial carcinoma (UC) of the bladder is the seventh most common type of cancer in men worldwide (1). Nearly one third of all patients undergoing radical surgery for muscleinvasive bladder cancer develop local recurrence with or without distant metastasis (2). On the other hand, UC of the upper urinary tract is a relatively rare disease, accounting for

This article is freely accessible online.

Correspondence to: Yasuyoshi Miyata, MD, Ph.D., Department of Urology, Nagasaki University Graduate School of Biomedical Sciences, 1-7-1 Sakamoto, Nagasaki 852-8501, Japan. Tel: +81 958197340, Fax: +81 958197343, e-mail: yasu-myt@nagasakiu.ac.jp

Key Words: Gemcitabine, paclitaxel, human antigen-R, class III $\beta$ tubulin, urothelial cancer. only $5-10 \%$ of all UC; $60 \%$ of these tumors are invasive at diagnosis (3). In view of the poor prognosis of advanced UC, it is compelling to explore newer treatment strategies. Platinum-based combination chemotherapy is the most common first-line therapy for patients with advanced UC. However, it offers a modest duration of response with unsatisfactory survival benefits. The median time to treatment failure and overall survival (OS) in patients with advanced UC treated with cisplatin-based chemotherapy are reported to be 5 and 14 months, respectively (4).

Various second-line chemotherapy agents, including gemcitabine, paclitaxel, docetaxel, and vinflunine, have been studied $(5,6)$. In addition, several molecular targeted therapies, singly or in combination with chemotherapy, have been studied worldwide $(7,8)$. In recent years, immune checkpoint inhibitors of programmed cell death-1 (PD1)/programmed cell death-ligand-1 (PD-L1) demonstrated significant survival benefits in patients with metastatic UC whose disease progressed during or after platinum-based chemotherapy (9-11). However, their response rates were modest, at approximately $20 \%$ (9-11). Additionally, according to a report, treatment with immune check point inhibitors is associated with severe treatment-related adverse events in 15$18 \%$ of patients $(10,11)$. Furthermore, these agents are often unsuitable for patients with poor performance status (PS), owing to difficulties in prompt and appropriate action during adverse events. The costs of therapy with check point inhibitors are also considerably high; this poses a major hurdle to treatment, particularly in developing countries. Therefore, best supportive care (BSC) is the most common treatment option for the majority of patients with poor PS, owing to older age, poor general condition, or both.

Among those individuals with a PS of 2 or 3 who may be fit to receive second-line chemotherapy, treatment is often not considered feasible as there is very little information available on the safety and efficacy of chemotherapy for these patients. On the other hand, careful judgement on the feasibility of administering second-line chemotherapy is 
essential for such patients, as the treatment may cause more adverse events than clinical benefit in these individuals. Therefore, a search for predictive markers for clinical benefit is of utmost necessity in the choice of therapy in patients with advanced UC and a PS of 2 or 3 .

We reported that human antigen- $\mathrm{R}$ (HuR) expression is a useful predictor of response to gemcitabine-based chemotherapy in patients with cisplatin-resistant UC (12). Class III $\beta$-tubulin (TUBB3) expression was also reported to predict the clinical benefits of paclitaxel-based second-line chemotherapy in these patients (13). On the other hand, we had reported the benefits and safety of combined low-dose gemcitabine $\left(700 \mathrm{mg} / \mathrm{m}^{2}\right.$ on day 1$)$, and paclitaxel $\left(70 \mathrm{mg} / \mathrm{m}^{2}\right.$ on day 1) administered in a 2 weeks-on and 2 weeks-off schedule (named LD-GP therapy) as second-line chemotherapy in patients with platinum-resistant UC (5). In addition, we reported the safety and efficacy of combined lowdose gemcitabine $\left(700 \mathrm{mg} / \mathrm{m}^{2}\right.$ on day 1$)$, paclitaxel $\left(70 \mathrm{mg} / \mathrm{m}^{2}\right.$ on day 1), and sorafenib (400 mg/day on days 8 to 22) every 28 days in such patients (7). However, in those two clinical trials, only $10 \%$ of patients in the study population had a PS of 2, and no patient had PS 3 . The tolerability of this regimen has therefore not been adequately tested in patients with a PS of 2 or 3 , particularly in those with a PS of 3. Owing to these limitations, we assessed a new experimental regimen (combination therapy of low-dose gemcitabine and paclitaxel every 4 weeks) at our hospital for some patients with PS 2 and almost all of those with PS 3.

The primary aim of the present study was to clarify the safety and efficacy of this experimental regimen in patients with platinum-resistant UC with a PS of 2 or 3 . Changes in quality of life (QoL) were also evaluated before and after this therapy. We additionally investigated the predictive values of HuR and TUBB3 expression for overall survival in these patients.

\section{Patients and Methods}

Patients. A total of 102 patients with advanced UC who had received first-line platinum-based chemotherapy at the Nagasaki University Hospital were enrolled in the study. All tumors had been histologically diagnosed as UC; patients with squamous celI or adenocarcinomas were excluded from this study. The experimental group enrolled 30 patients who were administered gemcitabine $\left(700 \mathrm{mg} / \mathrm{m}^{2}\right.$ on day 1$)$ and paclitaxel $\left(70 \mathrm{mg} / \mathrm{m}^{2}\right.$ on day 1$)$ every 4 weeks as second-line therapy between April 2009 and December 2016. In the chemotherapy control group, 28 patients were treated with LD-GP therapy and 14 patients received other agents (two, five, and seven patients received paclitaxel, gemcitabine with paclitaxel, and carboplatin, respectively). Based on our Institutional policy, these chemotherapy agents were continued until the patients, in conjunction with their families, wished to discontinue chemotherapy or until the PS worsened. In this study, 30 patients revived best supportive care (BSC) although we offered information on second-line therapy, and the major reason they chose BSC was because adverse events of first-line chemotherapy were severe. In our study population, all patients were judged as having muscle-invasive disease, and there was no significant difference in Tstage at diagnosis among these groups $(p=0.299)$. Similarly, grade and status of metastasis at diagnosis were similar among these four groups ( $p=0.306$ and 0.573 , respectively).

All patients underwent computed tomography with or without magnetic resonance imaging between 10 to 14 weeks after treatment completion to determine the in-field tumor response. The local response was assessed using the Response Evaluation Criteria in Solid Tumors (RECIST) guideline version 1.1 (14). Based on the guidelines, complete response was defined as the disappearance of all target lesions and reduction of any pathological lymph nodes to below $10 \mathrm{~mm}$ in the short axis. Partial response (PR) was defined as a decrease in the sum of the longest tumor diameters by at least $30 \%$. Stable disease (SD) was defined as neither enough tumor shrinkage to qualify as PR nor enough increase in size to qualify as progressive disease (PD), defined as an increase in the sum of longest tumor diameters by at least $20 \%$. In addition to the relative increase of $20 \%$, the sum also had to demonstrate an absolute increase of at least $5 \mathrm{~mm}$. The appearance of new lesion(s) was also considered progression.

Toxicities were graded using the Common Toxicity Criteria of the National Cancer Institute (version 4.0) (15). The QoL was evaluated using the Medical Outcomes Study Questionnaire Short Form 36 (SF-36) (16); the data were collected on the day before the first cycle was started, and again at 8 weeks after starting therapy.

Immunohistochemistry. The expression of HuR and TUBB3 were evaluated semi-quantitatively as described in our previous reports $(13,17)$. Immunohistochemistry was performed using formalinfixed and paraffin-embedded specimens. The expression profiles were evaluated according to the staining intensity and the percentage of positively stained cancer cells. In this study, we considered the expression of HuR to be high when cytoplasmic staining was moderate or intense in at least 10 to $50 \%$ of cells. For TUBB3, staining intensity was graded on a scale of 0 to 2 (no staining $=0$, weak $=1$, and strong $=2$ ), and the percentage of stained cancer cells was scored on a scale of 0 to $3(0=$ none, $1=1$ to $10 \%$, $2=11$ to $50 \%$, and $3=51$ to $100 \%$ ). If the product of the scores of staining intensity and percentage of stained cancer cells was between 4 and 6 , these tumors were considered to have high TUBB3 expression.

Ethics and statistical analyses. The study was conducted according to the Helsinki II Declaration and it was approved by the Ethics Review Committee of the Nagasaki University Hospital (no. 12052899). Written informed consent was obtained from all the patients involved in our study before their enrollment. The MannWhitney $U$-test was used for analysis of the continuous variables. The Chi-square test and the Fisher's exact test were used for comparison of the categorical variables. Kaplan-Meier curves and the log-rank pvalue were used for survival analyses. All statistical analyses were performed with the statistical software package StatView for Windows (version 5.0; Abacus Concept, Inc., Berkeley, CA, USA).

\section{Results}

Patient background. Patient background characteristics and PS after first-line chemotherapy for our study population are shown in Table I. The WHO PS in this study population was 
Table I. Patient background characteristics and performance status (PS) after first-line chemotherapy.

\begin{tabular}{|c|c|c|c|c|c|c|c|}
\hline & & \multirow[b]{2}{*}{$\begin{array}{c}\text { Whole cohort, } \\
\text { n }(\%)\end{array}$} & \multicolumn{4}{|c|}{ Therapy, n (\%) } & \multirow[b]{2}{*}{$p$-Value } \\
\hline & & & $\begin{array}{c}\mathrm{BSC} \\
(\mathrm{n}=30)\end{array}$ & $\begin{array}{l}\text { LD-GP } \\
(\mathrm{n}=28)\end{array}$ & $\begin{array}{l}\text { Other regimes } \\
\quad(\mathrm{n}=14)\end{array}$ & $\begin{array}{l}\text { Experimental } \\
\quad(\mathrm{n}=30)\end{array}$ & \\
\hline \multirow[t]{2}{*}{ Age; n (\%) } & $\leq 75$ Years & $37(36.3)$ & $12(40.0)$ & $11(39.3)$ & $8(57.1)$ & $6(20.0)$ & \multirow[t]{2}{*}{0.095} \\
\hline & $>75$ Years & $65(63.7)$ & $18(60.0)$ & $17(60.7)$ & $6(42.9)$ & $24(80.0)$ & \\
\hline \multirow[t]{2}{*}{ Gender, n (\%) } & Male & $72(70.6)$ & $24(80.0)$ & 19 (67.9) & $10(71.4)$ & $18(60.0)$ & \multirow[t]{2}{*}{0.407} \\
\hline & Female & $31(30.4)$ & $6(20.0)$ & $9(32.1)$ & $4(28.6)$ & $12(40.0)$ & \\
\hline \multirow[t]{2}{*}{ PS; n (\%) } & 2 & $67(65.7)$ & $15(50.0)$ & $21(75.0)$ & $8(57.1)$ & $23(76.7)$ & \multirow[t]{2}{*}{0.093} \\
\hline & 3 & $35(34.3)$ & $15(50.0)$ & $7(25.0)$ & $6(36.7)$ & $7(23.3)$ & \\
\hline \multirow[t]{2}{*}{ Metastasis, n (\%) } & $\leq 2$ Organs & $74(72.5)$ & $23(76.7)$ & $20(71.4)$ & $9(64.3)$ & $22(73.3)$ & \multirow[t]{2}{*}{0.859} \\
\hline & $\geq 3$ Organs & $28(27.5)$ & $7(23.3)$ & $8(28.6)$ & $5(35.7)$ & $8(26.7)$ & \\
\hline
\end{tabular}

BSC: Best supportive care; LD-GP: low-dose, gemcitabine and paclitaxel.

2 and 3 in $67(65.7 \%)$ and $35(34.30 \%)$ patients, respectively, and there was no significant difference in baseline characteristics between treatment groups (Table I). Although this cohort was not randomized, there were no statistical differences in terms of gender and age at baseline between the group receiving second-line chemotherapy and that receiving BSC. The median follow-up period was 10 months [interquartile range $(\mathrm{IQR})=4-19$ months] .

Safety and quality of life. Fatigue $(\mathrm{n}=18,60.0 \%)$ and anorexia $(n=8,26.7 \%)$ were the most frequent adverse events in the experimental group. The incidence of adverse events in this group is shown in Table II. Among hematological adverse events, neutropenia occurred in six patients (20.0\%). However, no patients in this study population had any severe (grade 3 or 4 ) adverse event. One patient from this group discontinued treatment; however, this was not due to any adverse event.

In the QoL analyses, scores on all the SF-36 items decreased after therapy (Figure 1). After treatment, scores on the items "role-physical" and "vitality" in particular were found to be lower than the pre-treatment scores of the same items. However, these differences were not statistically significant ( $p=0.093$ and 0.092 , respectively). With regard to role of emotion, the score after treatment was higher than that before therapy. This difference was also not statistically significant $(p=0.098)$.

Efficacy. Among the patients receiving chemotherapy in the experimental group, PR was noted in one patient $(3.3 \%)$. However, no patients achieved CR. PD and SD were recorded in eight $(26.7 \%)$ and 21 (70.0\%) patients, respectively. In the patients with $\mathrm{PS} 2, \mathrm{PR}, \mathrm{SD}$, and PD were obtained in one $(4.3 \%), 16(69.6 \%)$, and six (26.1\%) patients, respectively. In patients with PS $3, \mathrm{PR}, \mathrm{SD}$, and PD
Table II. Frequency of adverse events

\begin{tabular}{lccc}
\hline & \multicolumn{3}{c}{ Number of patients $(\%)$} \\
\cline { 2 - 4 } & Grade 1 & Grade 2 & Total \\
\hline Hematological & & $3(10.0)$ & $6(20.0)$ \\
Neutropenia & $3(10.0)$ & $2(6.7)$ & $5(16.7)$ \\
Anemia & $3(10.0)$ & $2(6.7)$ & $5(16.7)$ \\
Thrombopenia & $3(10.0)$ & & \\
Non-hematological & $10(33.3)$ & $8(26.7)$ & $18(60.0)$ \\
Fatigue & $5(16.7)$ & $3(10.0)$ & $8(26.7)$ \\
Anorexia & $2(6.7)$ & $1(3.3)$ & $3(10.0)$ \\
Nausea & $2(6.7)$ & $0(0.0)$ & $2(6.7)$ \\
Alopecia & $1(3.3)$ & $0(0.0)$ & $1(3.3)$ \\
Hand-foot reaction & & & \\
\hline
\end{tabular}

were obtained in $0(0 \%), 5(71.4 \%)$, and $2(28.6 \%)$ patients, respectively. No significant difference was therefore evident between patients with PS 2 and those with PS $3(p=0.852)$.

In the experimental group, survival rates at 6 months after initiation of second-line therapy in patients with PS 2 was $76.1 \%$. Corresponding survival rates in patients receiving BSC, those receiving other regimens, and the LD-GP group, were $64.6 \%, 75.0 \%$, and $70.4 \%$, respectively. In patients with PS 2, survival rates at 12 months after treatment for the experimental and the LD-GP groups were $59.8 \%$ and $54.1 \%$, respectively. In contrast, these rates in the groups receiving BSC and other regimens were $21.5 \%$ and $37.5 \%$, respectively. The Kaplan-Meier survival curves showed that the overall survival rate for the experimental group was significantly higher $(p<0.001)$ than that of the BSC-treated group. However, the survival curves of the experimental group and the LD-GP group were similar $(p=0.426)$ (Figure 2A). In 


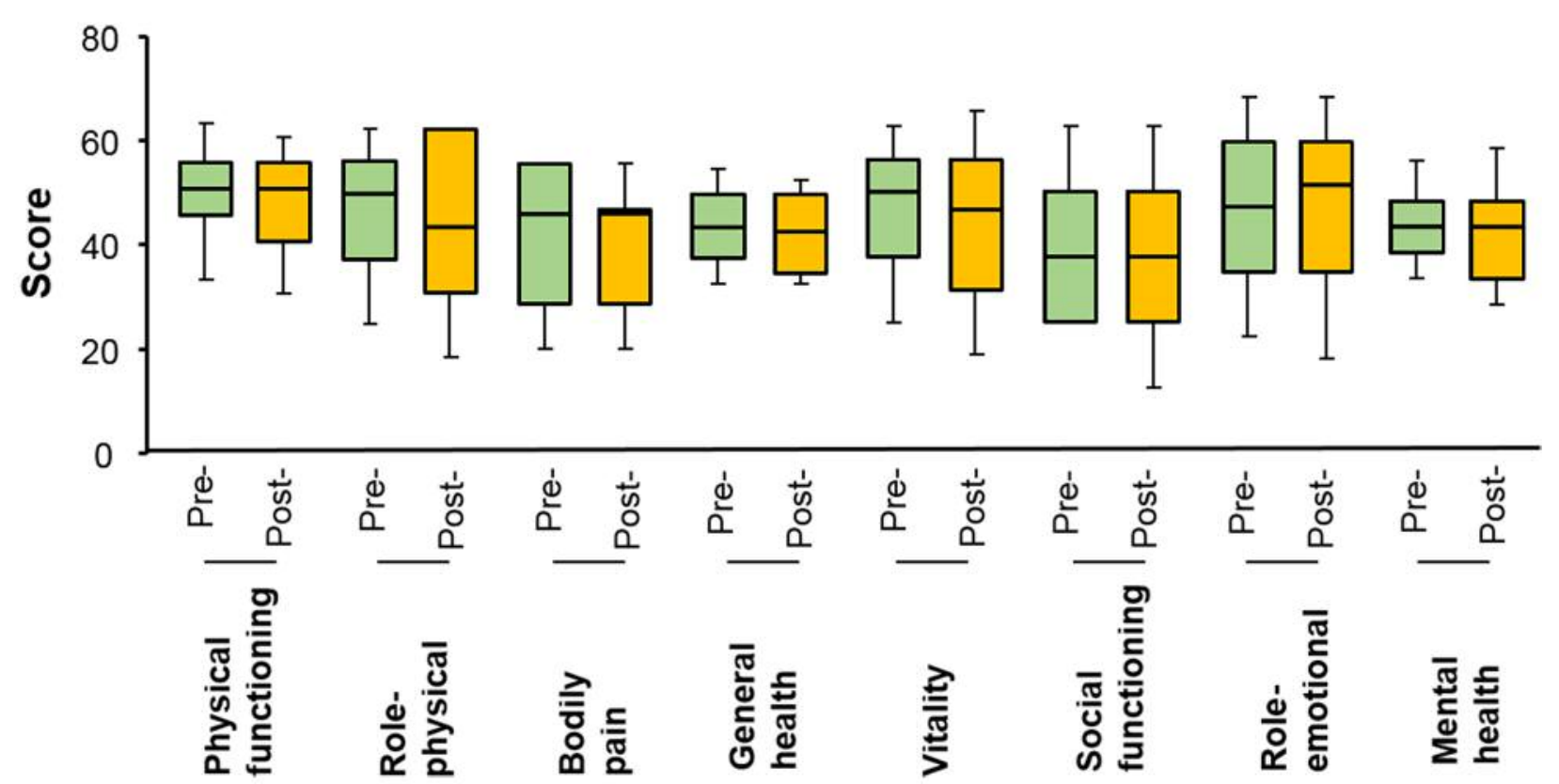

Figure 1. Qualify of life evaluated as by SF-36 after therapy. All scores on all items decreased after the therapy; however, such changes did not reach a significant level (all $p>0.09$ ). In these plots, median levels are indicated with horizontal bars in the boxes. The vertical bars indicate the range and the boundaries of the boxes represent the first and third quartiles.

patients with PS 2 (Figure 2B), the survival rate for the experimental group was significantly better than for other groups $(p=0.041)$. However, the difference between the experimental group and the LD-GP group was not significant $(p=0.815)$. In patients with PS 3, statistical analysis showed that the overall survival for the experimental group was significantly better $(p=0.030)$ than that of the other groups (Figure 2C). Although the survival curves for the experimental group were better than those of the LD-GP group, the difference did not attain statistical significance $(p=0.068)$.

Predictive value of $H u R$ and TUBB3. The survival curves according to the expression of $\mathrm{Hu}$, and TUBB3 showed that individually, neither the expression of $\mathrm{HuR}$ nor that of TUBB3 was significantly associated with overall survival ( $p=0.085$ and 0.073 , respectively, Figure $3 \mathrm{~A}$ and $\mathrm{B}$ ). However, when considered together, the overall survival of patients with low HuR and high TUBB3 expression was remarkably worse $(p<0.001)$ compared to those with other expression patterns (Figure 3C).

\section{Discussion}

There is a general agreement that UC is common in the elderly $(1,3)$. Indeed, in the present study, the mean age at initiation of second-line chemotherapy was over 75 years.
However, the median age of patients with UC was under 65 years in many second-line chemotherapy trials $(10,18,19)$. In addition, prospective studies on second-line chemotherapy have often excluded patients with WHO PS scores of 2 or higher or Karnofsky PS scores below 60, as these studies were designed to assess only the risk of adverse events and survival benefits (19). Usually, older patients are considered suitable candidates for BSC, and not chemotherapy, regardless of PS. However, from the patients' perspective, many often hope to receive some form of second-line therapy. Our findings support the fact that some of such patients experienced improved QoL and had noticeable pain relief after second-line chemotherapy $(5,7)$. We, therefore, believe that it is essential for urologists and medical oncologists to be aware of second-line therapy options for patients with platinum-resistant UC who have a PS of 2 or 3 .

The safety and costs of chemotherapy are major issues for decision-making. Regimens associated with high risk of adverse events, and those which are not cost-effective, should not be preferred choices when offering second-line therapy. In the present study, the experimental regimen was associated with a relatively high incidence of fatigue (59.5\%). However, severe adverse events including hematological toxicities were not seen. We have already reported the benefit and safety of the LD-GP regimen as second-line chemotherapy for patients with advanced platinum-resistant UC (5). In that previous 
A

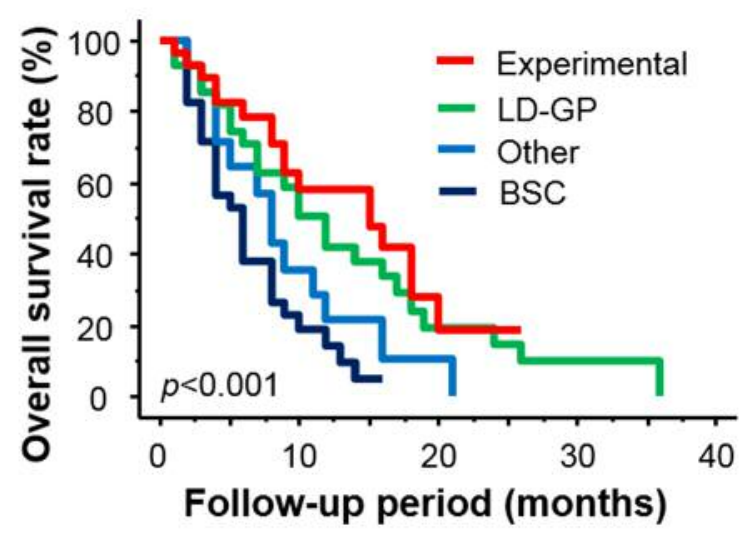

B

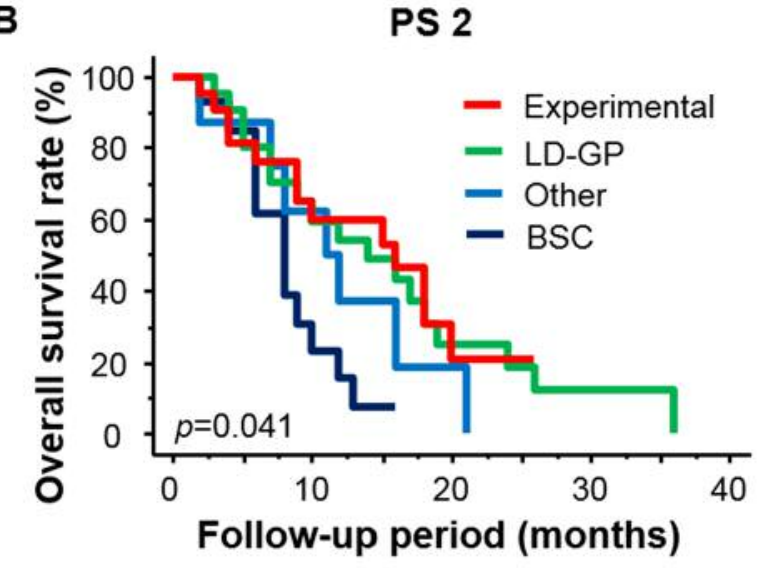

C

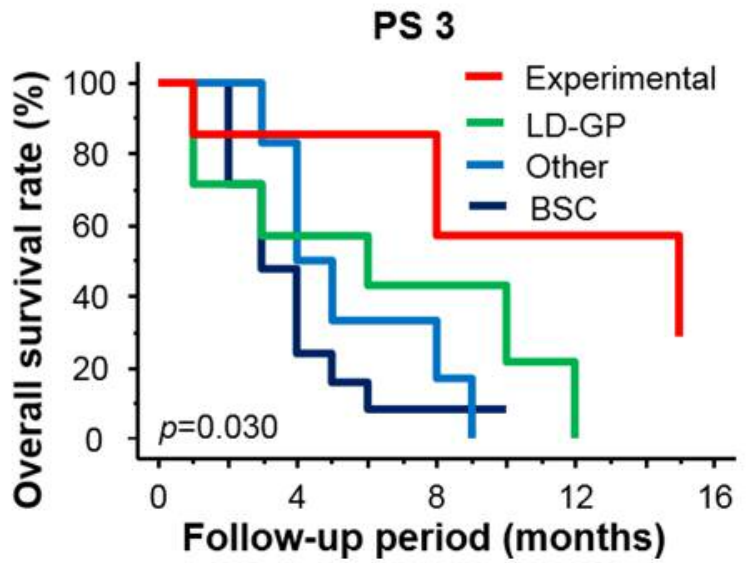

Figure 2. Kaplan-Meier survival curves for overall survival from starting of the therapy for the whole patient cohort $(A)$, and for patients with performance status $2(B)$ and $3(C)$. In sub-group analysis, the overall survival period for the experimental group was significantly better than those for other groups. LD-GP: Low-dose gemcitabine and paclitaxel; BSC: best supportive care. p-VaIues are for experimental group versus: *BSC; \#all other groups.

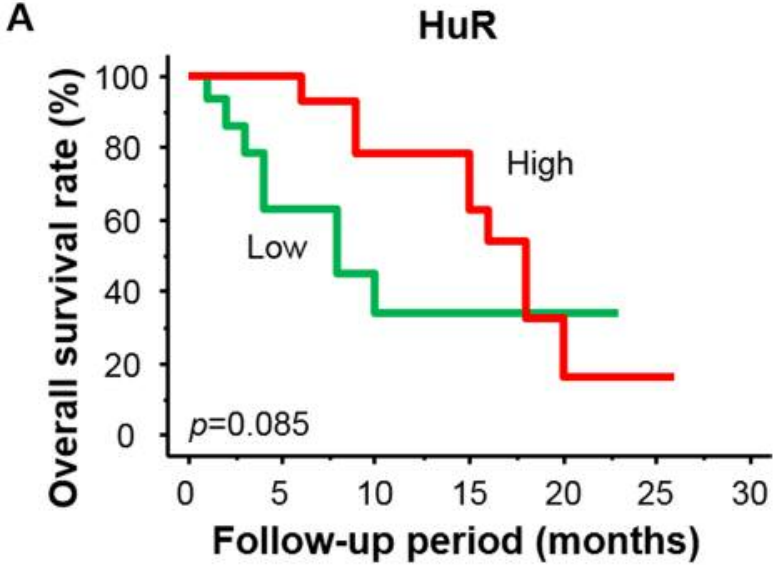

B

TUBB3

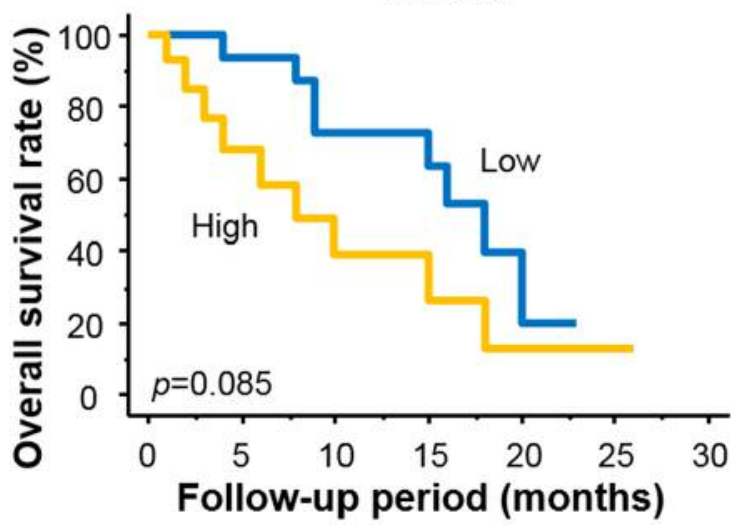

C

HuR/TUBB3

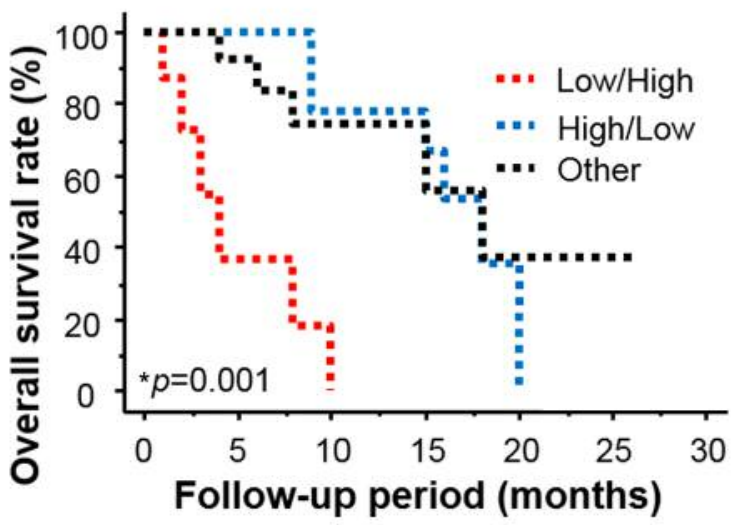

Figure 3. Relationship between overall survival periods and expression pattern of human antigen-R (HUR) (A), class III $\beta$-tubulin (TUBB3) (B), alone and combined $(C)$ in the experimental group. Considered alone, expression of HUR and TUBB3 were not associated with overall survival ( $A$ and $B)$. In contrast, overall survival of patients with low HUR/high TUBB3 expression was remarkably shorter than that of those with any other pattern* $(C)$. 
study, LD-GP offered a median OS of 12 months, however, with severe neutropenia (grade 3 or higher) occurring in $14.3 \%$ of those treated. The rates of anemia and thrombocytopenia were both 5.7\%; nausea and vomiting, and skin rash were both noted in $2.9 \%$ of patients receiving this regimen. We had also reported on the safety and efficacy of combination therapy with low-dose gemcitabine, paclitaxel, and sorafenib in patients with cisplatin-resistant UC (7). In that study, patients were treated with gemcitabine $\left(700 \mathrm{mg} / \mathrm{m}^{2}\right.$ on day 1$)$, paclitaxel $\left(70 \mathrm{mg} / \mathrm{m}^{2}\right.$ on day 1), and sorafenib (400 mg/day on from days 8 to 22 ) every 28 days. The triple-agent regimen offered a median OS of 7 months. Severe anemia and thrombocytopenia were noted in $10 \%$ and $5 \%$, respectively. Among the non-hematological events, the most common were fatigue $(10.0 \%)$ and anorexia $(10.0 \%)$. Other events accounted for $15.0 \%$ of the AEs. These two previous studies did not include any patients with PS 3 . Thus, the safety of the experimental combined four-weekly low-dose gemcitabine and paclitaxel regimen in the current study was better tested than that of the previous combined gemcitabine and paclitaxel regimen.

Despite various available treatments, survival after secondline therapy in patients with advanced UC is unfortunately short. Therefore, maintenance of QoL is of the utmost importance. However, there are few reports on the improvement of QoL with second-line chemotherapy in patients with platinum-resistant UC with a PS of 2 or 3 . It has been reported that in patients with platinum-resistant $\mathrm{UC}$, two cycles of combination therapy (gemcitabine $1,000 \mathrm{mg} / \mathrm{m}^{2}$ on days 1,8 , and 15 , and paclitaxel $200 \mathrm{mg} / \mathrm{m}^{2}$ on day 1 of each 21-day cycle) did not significantly improve scores on all items of the SF-36 (20). However, in that study, this regimen was used in the third-line setting and the study population did not include patients with PS 2 or 3 . Findings from the present study confirm these results, and suggest minimal worsening of QoL with this regimen and good tolerability among patients with PS 2 and 3 .

Tumor- or patient-related predictive factors that may help select meaningful treatment strategies are of particular importance in patients with PS 2 or 3 . The ability to predict clinical benefits of treatment, including survival benefit, will offer a useful guide to decision-making. We have reported that HuR and TUBB3 are useful predictors of outcome with regard to gemcitabine- and paclitaxel-based regimens in patients with UC $(13,17)$. Similar findings were also reported in other types of cancer (21-23). However, the present study showed that neither of these markers was individually significantly associated with OS. We speculate that differences in clinicopathological features, patient background, PS, and dosage are probably responsible for these differences. On the other hand, in combination, these two markers demonstrated predictive value with regard to overall survival in patients with UC with a PS of 2 or 3 .
In recent years, various potential targeted therapeutics for UC have been suggested by in vivo study and translational research $(24,25)$. In addition, clinical trials on combined immune checkpoint inhibitor and chemotherapy or molecular targeted therapy and combination of different chemotherapeutic agents are ongoing and being developed for metastatic bladder cancer (26-29). These new regimens are expected to improve the prognosis of these patients. However, immune checkpoint inhibitors and molecular targeted agents are usually expensive. In addition, they often lead to severe adverse events. We speculate that regimens including these agents may not be suitable for patients with a PS of 2 or 3, owing to cost-benefit and safety considerations. Therefore, we believe that our regimen (lowdose gemcitabine and paclitaxel every 4 weeks) offers many advantages to these patients in terms of cost, safety, and efficacy, as compared to other regimens.

This study has several limitations. Firstly, the data on clinical benefits and safety were evaluated retrospectively and this was not a randomized trial. Secondly, the number of patients in this study was relatively low. However, clinical data regarding the efficacy and safety of second-line therapy in patients with UC with PS 2 or 3 are scarce. In recent years, newly developed therapies including immune checkpoint inhibitors are being used in patients with platinum-resistant UC. However, these therapies are not recommended for those with PS 2 or 3 because of their toxicities and costs. Therefore, despite several limitations, we believe that our results confirm this as a feasible alternative treatment strategy for these patients.

\section{Conclusion}

Treatment with combined low-dose gemcitabine and paclitaxel every 4 weeks was well tolerated and the QoL was maintained after treatment. Although this was not a randomized study, our results showed that this regimen improved prognosis. Interestingly, some patients showed relatively longer survival periods. We believe that this treatment regimen is suitable for use as second-line therapy in patients with advanced UC having a PS of 2 or 3 . Furthermore, the combined expression pattern of HUR and TUBB3 may be useful in predicting the patient's prognosis with this regimen.

\section{Conflicts of Interest}

None of the Authors have any conflicts of interest in regard to this study.

\section{Acknowledgements}

The Authors wish to thank Ms. Mitsuko Yoneda for technical support. This study was supported in part by funds provided by KAKENHI (Grant-in-Aid for Exploratory Research) to Yasuyoshi Miyata (25462487). 


\section{Authors' Contributions}

Study concept: YM. Study deign: YM. Clinical data collection: TM, $\mathrm{KM}, \mathrm{YN}$, and KO. Immunohistochemical analyses: YM, AA, YN, YM, AO, TY, and KM. Statistical analyses: YM and TM. Article preparation: KA, YM, and YN. Article editing: KO and HS. Article review: HS. All Authors read and approved the final article.

\section{References}

1 Babjuk M, Böhle A, Burger M, Capoun O, Cohen D, Compérat EM, Hernández V, Kaasinen E, Palou J, Rouprêt M, van Rhijn BW, Shariat SF, Soukup V, Sylvester RJ and Zigeuner R: EAU Guidelines on non-muscle-invasive urothelial carcinoma of the bladder: Update 2016: Eur Urol 71: 447-461, 2017. PMID: 27324428. DOI: 10.1016/j.eururo.2016.05.041

2 Stein JP, Lieskovsky G, Cote R, Groshen S, Feng AC, Boyd S, Skinner E, Bochner B, Thangathurai D, Mikhail M, Raghavan $\mathrm{D}$ and Skinner DG: Radical cystectomy in the treatment of invasive bladder cancer: Long-term results in 1,054 patients. J Clin Oncol 19: 666-675, 2001. PMID: 11157016.

3 Rouprêt M, Babjuk M, Compérat E, Zigeuner R, Sylvester RJ, Burger M, Cowan NC, Gontero P, Van Rhijn BWG, Mostafid AH, Palou J and Shariat SF: European Association of Urology guidelines on upper urinary tract urothelial carcinoma: 2017 Update. Eur Urol 73: 111-122, 2018. PMID: 28867446. DOI: 10.1016/j.eururo.2017.07.036

4 von der Maase H, Hansen SW, Roberts JT, Dogliotti L, Oliver T, Moore MJ, Bodrogi I, Albers P, Knuth A, Lippert CM, Kerbrat P, Sanchez Rovira P, Wersall P, Cleall SP, Roychowdhury DF, Tomlin I, Visseren-Grul CM and Conte PF: Gemcitabine and cisplatin versus methotrexate, vinblastine, doxorubicin and cisplatin in advanced or metastatic bladder cancer: results of a large, randomized, multinational, multicenter, phase III study. J Clin Oncol 18: 3068-3077, 2000. PMID: 11001674.

5 Miyata Y, Nomata K, Ohba K, Matsuo T, Sagara Y, Kanetake H and Sakai H: Use of low-dose combined therapy with gemcitabine and paclitaxel for advanced urothelial cancer patients with resistance to cisplatin-containing therapy: A retrospective analysis. Cancer Chemother Pharmacol 70: 451459, 2012. PMID: 22864875. DOI: 10.1007/s00280-012-1938-3

6 Furubayashi N, Negishi T, Yamashita T, Kusano S, Taguchi K, Shimokawa M and Nakamura M: The combination of paclitaxel and carboplatin as second-line chemotherapy can be a preferred regimen for patients with urothelial carcinoma after the failure of gemcitabine and cisplatin chemotherapy. Mol Clin Oncol 7: 112-118, 2017. PMID: 29285384. DOI: $10.3892 / \mathrm{mco} .2017 .1452$

7 Miyata Y, Asai A, Mitsunari K, Matsuo T, Ohba K and Sakai H: Safety and efficacy of combination therapy with low-dose gemcitabine, paclitaxel and sorafenib in patients with cisplatinresistant urothelial cancer. Med Oncol 32: 235, 2015. PMID: 26310889. DOI: 10.1007/s12032-015-0683-y

8 Jones RJ, Hussain SA, Protheroe AS, Birtle A, Chakraborti P, Huddart RA, Jagdev S, Bahl A, Stockdale A, Sundar S, Crabb SJ, Dixon-Hughes J, Alexander L, Morris A, Kelly C, Stobo J, Paul J and Powles T: Randomized phase II study investigating pazopanib versus weekly paclitaxel in relapsed or progressive urothelial cancer. J Clin Oncol 35: 1770-1777, 2017. PMID: 28402747. DOI: $10.1200 /$ JCO.2016.70.7828
9 Rosenberg JE, Hoffman-Censits J, Powles T, van der Heijden MS, Balar AV, Necchi A, Dawson N, O’Donnell PH, Balmanoukian A, Loriot Y, Srinivas S, Retz MM, Grivas P, Joseph RW, Galsky MD, Fleming MT, Petrylak DP, Perez-Gracia JL, Burris HA, Castellano D, Canil C, Bellmunt J, Bajorin D, Nickles D, Bourgon R, Frampton GM, Cui N, Mariathasan S, Abidoye O, Fine GD and Dreicer R: Atezolizumab in patients with locally advanced and metastatic urothelial carcinoma who have progressed following treatment with platinum-based chemotherapy: A single-arm, multicentre, phase 2 trial. Lancet 387: 1909-1920, 2016. PMID: 26952546. DOI: 10.1016/S0140-6736(16)00561-4

10 Bellmunt J, Théodore C, Demkov T, Fradet Y, Lee JL, Fong L, Vogelzang NJ, Climent MA, Petrylak DP, Choueiri TK, Necchi A, Gerritsen W, Gurney H, Quinn DI, Culine S, Sternberg CN, Mai Y, Poehlein CH, Perini RF and Bajorin DF: Phase III trial of vinflunine plus best supportive care compared with best supportive care alone after a platinum-containing regimen in patients with advanced transitional cell carcinoma of the urothelial tract. J Clin Oncol 27: 4454-4461, 2009. PMID: 19687335.

11 Sharma P, Retz M, Siefker-Radtke A, Baron A, Necchi A, Bedke J, Plimack ER, Vaena D, Grimm MO, Bracarda S, Arranz JÁ, Pal S, Ohyama C, Saci A, Qu X, Lambert A, Krishnan S, Azrilevich A and Galsky MD: Nivolumab in metastatic urothelial carcinoma after platinum therapy (CheckMate 275): A multicentre, single-arm, phase 2 trial. Lancet Oncol 18: 312-322, 2017. PMID: 28131785. DOI: 10.1016/S1470-2045(17)30065-7

12 Miyata Y, Mitsunari K, Akihiro A, Watanabe SI, Matsuo T, Ohba $\mathrm{K}$ and Sakai $\mathrm{H}$ : Human antigen $\mathrm{R}$ as a predictive marker for response to gemcitabine-based chemotherapy in advanced cisplatin-resistant urothelial cancer. Oncol Lett 13: 811-818, 2017. PMID: 28356963. DOI: 10.3892/ol.2016.5484

13 Miyata Y, Matsuo T, Nakamura Y, Yasuda T, Ohba K, Takehara $\mathrm{K}$ and Sakai H: Expression of class III beta-tubulin predicts prognosis in patients with cisplatin-resistant bladder cancer receiving paclitaxel-based second-line chemotherapy. Anticancer Res 38: 1629-1635, 2018. PMID: 29491095.

14 Eisenhauer EA, Therasse P, Bogaerts J, Schwartz LH, Sargent D, Ford R, Dancey J, Arbuck S, Gwyther S, Mooney M, Rubinstein L, Shankar L, Dodd L, Kaplan R, Lacombe D and Verweij J: New response evaluation criteria in solid tumours: Revised RECIST guideline (version 1.1). Eur J Cancer 45: 228247, 2009. PMID: 19097774. DOI: 10.1016/j.ejca.2008.10.026

15. National Institutes of Health National Cancer Institute: Common Terminology Criteria for Adverse Events (CTCAE) Version 4.0., 2009. Available at: http://evs.nci.nih.gov/ftp1/CTCAE/CTCAE_ 4.03_2010-06-14_QuickReference_5x7.pdf

16. Fukuhara S, Ware JE Jr., Kosinski M, Wada S and Gandek B: Psychometric and clinical tests of validity of the Japanese SF36 Health Survey. J Clin Epidemiol 51: 1045-1053, 1998. PMID: 9817122. DOI: 10.1016/s0895-4356(98)00096-1

17. Yasuda T, Miyata Y, Nakamura Y, Sagara Y, Matsuo T, Ohba K and Sakai H: High consumption of green tea suppresses urinary tract recurrence of urothelial cancer via down-regulation of human antigen-R expression in never smokers. In Vivo 32: 721729, 2018. PMID: 29936451. DOI: 10.21873/invivo.11300

18. Uhm JE, Lim HY, Kim WS, Choi HY, Lee HM, Park BB, Park $\mathrm{K}$ and Kang WK: Paclitaxel with cisplatin as salvage treatment for patients with previously treated advanced transitional cell carcinoma of the urothelial tract. Neoplasia 9: 18-22, 2007. PMID: 17325740. 
19 Albers P, Park SI, Niegisch G, Fechner G, Steiner U, Lehmann J, Heimbach D, Heidenreich A, Fimmers R, Siener R and AUO Bladder Cancer Group: Randomized phase III trial of 2nd-line gemcitabine and paclitaxel chemotherapy in patients with advanced bladder cancer: Short-term versus prolonged treatment [German Association of Urological Oncology (AUO) trial AB 20/99]. Ann Oncol 22: 288-294, 2011. PMID: 20682548. DOI: 10.1093/annonc/mdq398

20 Naiki T, Iida K, Kawai N, Etani T ando R, Nagai T, Tanaka Y, Hamamoto S, Hamakawa T, Akita H, Sugiyama Y and Yasui T: A pilot study of gemcitabine and paclitaxel as third-line chemotherapy in metastatic urothelial carcinoma. J Rural Med 12: 105-111, 2017. PMID: 29255527. DOI: $10.2185 /$ jrm.2940

21 Kato A, Naiki-Ito A, Naitoh I, Hayashi K, Nakazawa T, Shimizu $\mathrm{S}$, Nishi Y, Okumura F, Inoue T, Takada $\mathrm{H}$, Kondo $\mathrm{H}$, Yoshida $\mathrm{M}$, Takahashi $\mathrm{S}$ and Joh T: The absence of class III $\beta$-tubulin is predictive of a favorable response to nab-paclitaxel and gemcitabine in patients with unresectable pancreatic ductal adenocarcinoma. Hum Pathol 74: 92-98, 2018. PMID: 29339176. DOI: 10.1016/j.humpath.2018.01.009

22 Toyota K, Murakami Y, Kondo N, Uemura K, Nakagawa N, Takahashi S and Sueda T: Cytoplasmic Hu-Antigen R (HuR) expression is associated with poor survival in patients with surgically resected cholangiocarcinoma treated with adjuvant gemcitabine-based chemotherapy. Ann Surg Oncol 25: 1202-1210, 2018. PMID: 29492748. DOI: 10.1245/s10434-018-6392-y

23 Nami B and Wang Z: Genetics and expression profile of the tubulin gene superfamily in breast cancer subtypes and its relation to taxane resistance. Cancers 10: pii: E274, 2018. PMID: 30126203. DOI: 10.3390/cancers10080274

24 Chiang $\mathrm{CH}$, Yeh CY, Chung JG, Chiang IT and Hsu FT: Amentoflavone induces apoptosis and reduces expression of anti-apoptotic and metastasis-associated proteins in bladder cancer. Anticancer Res 39: 3641-3649, 2019. PMID: 31262890. DOI: 10.21873 /anticanres.13512
25 Nakamura Y, Miyata Y, Takehara K, Asai A, Mitsunari K, Araki $\mathrm{K}$, Matsuo $\mathrm{T}$, Ohba $\mathrm{K}$ and Sakai $\mathrm{H}$ : The pathological significance and prognostic roles of thrombospondin-1 and -2 and 4N1K-peptide in bladder cancer. Anticancer Res 39: 23172324, 2019. PMID: 31092423. DOI: 10.21873/anticanres. 13348

26 Katz H, Wassie E and Alsharedi M: Checkpoint inhibitors: The new treatment paradigm for urothelial bladder cancer. Med Oncol 34: 170, 2017. PMID: 28864844. DOI: 10.1007/s12032017-1029-8

27 Godwin JL, Hoffman-Censits J and Plimack E: Recent developments in the treatment of advanced bladder cancer. Urol Oncol 36: 109-114, 2018. PMID: 29395962. DOI: 10.1016/ j.urolonc.2017.12.018

28 Massari F, Di Nunno V, Cubelli M, Santoni M, Fiorentino M, Montironi R, Cheng L, Lopez-Beltran A, Battelli N and Ardizzoni A: Immune checkpoint inhibitors for metastatic bladder cancer. Cancer Treat Rev 64: 11-20, 2018. PMID: 29407369. DOI: 10.1016/j.ctrv.2017.12.007

29 Necchi A, Pond GR, Raggi D, Giannatempo P, Vogelzang NJ, Grivas P, Galsky MD, Bellmunt J and Sonpavde G: Efficacy and safety of gemcitabine plus either taxane or carboplatin in the first-line setting of metastatic urothelial carcinoma: A systematic review and meta-analysis. Clin Genitourin Cancer 15: 23-30.e2, 2017. PMID: 27324051. DOI: 10.1016/j.clgc.2016.05.003

Received August 7, 2019 Revised September 12, 2019 Accepted September 19, 2019 